\title{
Optical Nonlinearity of Oxazine Dye Doped PMMA Films by Z-Scan Techniques
}

\author{
Amal Faisal Jaffar \\ Foundation of Technical Education, Institute of Medical Technology, Mansour Ministry \\ of High Education \& Scientific Researches. \\ E-mial:Amal_physics@yahoo.com.
}

\begin{abstract}
In this experimental work, a study (by using a high sensitive method known as Z-Scan technique) of the nonlinear optical properties for the laser dyes oxsazine in PMMA doped films with different concentrations with the solvent Chloroform.Z-scan experiment was performed using $\mathrm{CW}$ diode laser at $650 \mathrm{~nm}$ with the power output of $40 \mathrm{~mW}$, in two parts. The first part was done using a closed-aperture placed in front of the detector to measure the nonlinear refractive index. In the second part; the aperture in front the detector was removed (open aperture) to measure the nonlinear absorption coefficient. The experimental results for closed aperture show that the dye doped films exhibits negative refractive index (self_defocusing) for the law concentrations $\left(10^{-6}\right.$ $\& 10^{-5} \mathrm{M} / \mathrm{L}$ ), while the large concentrations $10^{-4} \& 10^{-3} \mathrm{M} / \mathrm{L}$ had damaged. The results show also that the nonlinear refractive index and the third order nonlinear susceptibility increased with the increasing concentration. This is due to the increasing of the film thickness which caused an increase in the nonlinear phase shift in the samples. For open aperture z-scan the results show that the samples exhibited saturation absorption. The samples of law concentrations have a large nonlinear optical effect, which can be a promising candidate for photonic device application.
\end{abstract}

Keyword: Z-scan technique, nonlinear refraction and nonlinear absorption, dye doped polymer films.

\section{Introduction}

Incorporating dye molecules into solid matrices have resulted in significant advances towards the development of practical tunable solid-state lasers .The use of a synthetic polymer host presents advantages as these materials show much better compatibility with organic laser dyes and are amenable to inexpensive fabrication techniques. These polymers provide an opportunity for the production of active elements that can effectively control the characteristics of laser radiation. [1]. Dye doped polymers find applications in the fields of modern photonic technology apart from its use as an alternative to solid state laser media. [2]. A nonlinear absorber of light has the unique property that its optical absorption can be altered by introducing changes in the intensity of radiation incident upon it. [3] Embedding it in third order susceptibility and nonlinear refractive index $\left(\mathrm{n}_{2}\right)$. Open aperture Z-scan technique is of either two types: saturable absorption (SA) and reverse saturable absorption solid matrices can modify the nonlinear optical proprieties of the dye. The basic absorption processes in dyes can be divided into linear and nonlinear absorption. Nonlinear optics is a material phenomenon in which intense light induces a nonlinear response in the medium, and in return the medium modifies the optical fields in a nonlinear way. In fact, all media are nonlinear to a certain degree $[4,5]$.

The $\mathrm{Z}$ scan technique is a simple, sensitive and popular experimental method to measure nonlinear optical prosperities (NLO) of materials. There were two parts of the Z-scan: closed aperture and open aperture. Closed aperture Z-scan helps to measure the sign and magnitude of both real \& imaginary part of (RSA) depending on the pump intensity and on the absorption cross section at the excitation wavelength [5].

Open aperture Z-scan helps to measure the nonlinear absorption coefficient $\beta_{2}$.

\section{Theory}

When the applied electric fields are sufficiently small, the electric polarization (p) is approximately linearly proportional to the applied electric field $\mathbf{E}$ : 
$\vec{P}=\chi \cdot \vec{E}$

Where $(\chi)$ is the electric susceptibility, it is a property of matter that describes the interaction of matter with the electric field of light [6].

This is the case of linear optics. However, when the applied electric fields are high enough, the induced polarization has a nonlinear dependence on these electric fields and can be expressed as a power series with respect to the electric field:

$$
\begin{gathered}
\overrightarrow{\mathrm{P}}=\chi^{(1)} \cdot \vec{E}+\chi^{(2)} \cdot \vec{E} \vec{E}+\chi^{(3)} \cdot \vec{E} \vec{E} \vec{E}+. . \\
p=P^{(1)}+P^{(2)}+P^{(3)}+\ldots \ldots \ldots \ldots \ldots \ldots
\end{gathered}
$$

Where $\chi^{(1)}$ is the linear susceptibility $\chi^{(2)}$ is the second order nonlinear susceptibility and $\chi^{(3)}$ is the third order nonlinear susceptibility. The third order nonlinear susceptibility is considered to be a complex tenser quantity:

$\chi^{(3)}=\mathrm{R} \chi^{(3)}+\operatorname{Im} \chi^{(3)}$

The real part is related to nonlinear refractive index $\mathrm{n}_{2}$ through:

$\mathrm{R} \chi^{(3)}=10^{-4} \epsilon_{\mathrm{o}} \mathrm{n}_{\mathrm{o}}^{2} \mathrm{c}^{2} \mathrm{n}_{2} / \pi$

Where $n_{0}$ is the linear refractive index, $\epsilon_{0}$ is the permittivity of free space, $\mathrm{c}$ is the speed of light in vacuum, $\mathrm{n}_{2}$ is the nonlinear refractive index [7]

The standard "closed aperture" Z-scan (i.e. aperture is placed in the far field) for determining nonlinear refraction is shown in Fig. (1), where the sample is moved along the propagation direction $\mathrm{z}$ while keeping the input pulse energy fixed. The normalized transmittance of the sample through the aperture is monitored in the far field as a function of the position $\mathrm{Z}$. The normalization is performed in such a way that the transmittance is unity for the sample far from focus where the nonlinearity is negligible [6]. An intensity dependent on the refractive index causes the beam radius of the transmitted beam to change while retaining the Gaussian profile.

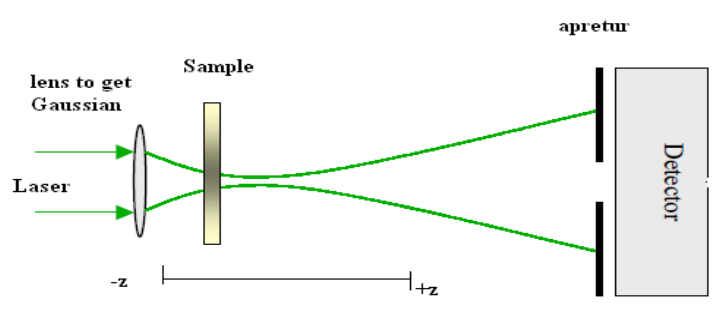

\section{Fig.(1) The scheme of the closed aperture z-scan [6].}

The size of the aperture is signified by its transmittance $(\mathrm{S})$, in the linear regime. In most reported experiments, $0.1<\mathrm{S}<0.5$ has been used for determining nonlinear refraction. [8].

The Z-scan technique is based on the transformation of phase distortions to amplitude distortions during beam propagation. A qualitative physical argument that explains the transmittance variations in the Z-scan experiment can be given as follows: Starting the scan from a distance far away from the focus (negative $\mathrm{z}$ ), the beam irradiance is low and negligible nonlinear refraction occurs leading to linear transmittance. As the sample is brought closer to the focus, the beam irradiance increases leading to self-lensing in the sample. A negative self-lensing (self-defocusing) prior to focus tends to collimate the beam and reduce the diffraction leading to a smaller beam at the aperture and an increased transmittance. As the scan continues and the sample crosses the focal plane to the right (positive $\mathrm{z}$ ), the same self-defocusing effect will tend to augment diffraction and reduce the aperture transmittance. A prefocal transmittance maximum (peak) and a post focal transmittance minimum (valley) will be, the $\mathrm{z}$ scan signature of a negative nonlinearity as shown by the dote line Fig.(2), while a positive one, following the same analogy, will give rise to an opposite valley-peak configuration,as shwon by Solid line Fig. (2). [8].

\section{Self Focusing and Defocusing}

Self-focusing (or Kerr-Lensing) is a consequence of the non-uniform spatial profile of the laser Gaussian beam. If the intensity of a transmitted light beam is sufficiently high, the refractive index change will modify the light propagation 
not only with respect to the polarization but in its geometrical properties too [3].

For a Gaussian beam of radius $\omega_{0}$ (beam waist) the Kerr-lens focal length is:

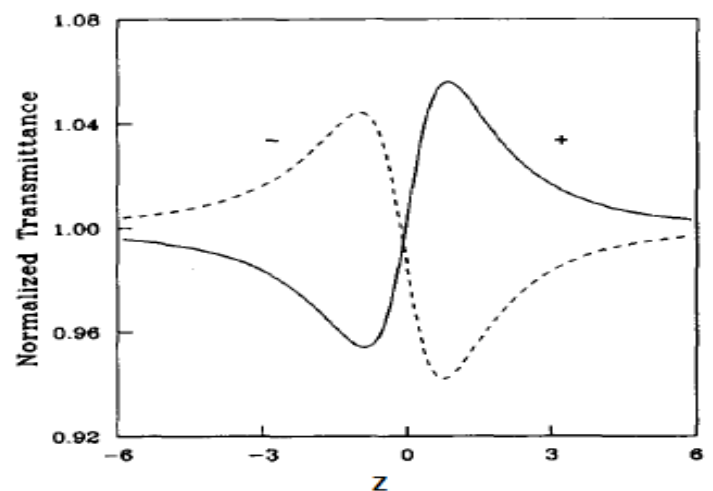

Fig.(2) Calculated Z-scan transmittance curves for a third order nonlinearity [9].

$\mathrm{F}=\mathrm{a} \omega_{\mathrm{o}}{ }^{2} / 4 \mathrm{Ln}_{2} \mathrm{I}$

Where $\mathrm{L}$ is the thickness of the nonlinear medium (sample), $\mathrm{I}$ is the irradiance and $\mathrm{a}$ is a correction term.

When $\mathrm{n}_{2}$ is negative, the above equation shows there will be a negative focal length and thus self de-focusing of the incident beam [9].

We define the change in transmittance between the peak and valley in a Z-scan as:

$\Delta \mathrm{T}_{\mathrm{pv}}=\mathrm{T}_{\mathrm{p}}-\mathrm{T}_{\mathrm{V}}$

where $T_{p}$ and $T_{v}$ are the normalized peak and valley transmittances as seen in Fig.(2). The empirically determined relation between the induced on axis phase shift, $\Delta \Phi_{0}$, and $\Delta \mathrm{T}_{\mathrm{pv}}$ for a third-order nonlinear refractive process in the absence of nonlinear absorption (NLA) is,

$$
\Delta T_{p v} \cong 0.406(1-S)^{0.27}\left|\Delta \phi_{o}\right|
$$

$S:$ the size of the aperture.

If the Z-scan aperture is closed to allow linear transmission of less than 10 percent or $0.1<\mathrm{S}<0.5$, then: $[10]$

$$
\Delta T_{p v} \cong 0.406 \mid \Delta \phi_{o}
$$

The nonlinear refractive index is calculated from the peak to valley difference of the normalized transmittance by the following formula: -

$\mathrm{n}_{2}=\Delta \phi_{o} / \mathrm{I}_{\mathrm{o}} \mathrm{L}_{\mathrm{eff}} \mathrm{k}$
$\mathrm{Io}=2 P_{\text {peak }} / \pi \omega_{o}^{2}$

$I_{o}$ is on axis irradiance,

$\omega_{o}:$ The beam radius at the focal point,

$k=\frac{2 \pi}{\lambda}$,

where $\lambda$, is the wavelength of the beam.

$L_{\text {eff }}$ : The effective length of the sample

(thickness), can determined from the following formula: [9]

$L_{e f f}=\left(1-e^{-\alpha_{o} L}\right) / \alpha_{o}$

Where, [9]:

L: the sample thickness,

$\alpha_{o}$ : Linear absorption coefficient,

$$
\alpha_{o}=\frac{1}{L \ln \left(\frac{1}{T}\right)}
$$

Where T: linear transmittance

\section{Experimental Section}

Oxazine is from xanthene family with fluorescence emission in the yellow -red region of the electromagnetic spectrum (570$650 \mathrm{~nm}$ ) are well known for their excellent laser performance in liquid solutions as well as in solid matrices [11], Fig.(3) shows its molecular structure.

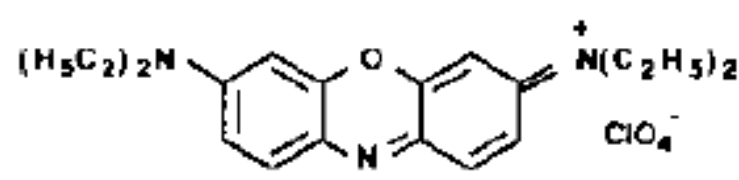

Fig. (3) The molecular structure of Oxazine, [12].

Polymethylmethacrylate (PMMA) is from ICI Company. The spectroscopic grade solvent Chloroform is from Lab-Scan LTd., Analitical Science HPLC Ireland-Dublin. In the present work, CW diode laser system is from Institute of Laser for Postgraduate Studies, Baghdad university ,Iraq, it is a:diode laser of wave length $650 \mathrm{~nm}$, max.Power is 50 mwatt, beam diameter: $(1.5 \mathrm{~mm})$, beam divergent (1.5) mrad, Ac: $220-240$ volt, frequency: $50-60 \mathrm{~Hz}$ of $250 \mathrm{~mA}$. 
Solution of concentrations $\left(10^{-6}, 10^{-5}, 10^{-4}\right.$, $10^{-3}$ ) $\mathrm{M} / 1$ in Chloroform where prepared by weighting amount of the material by using a matter balance having a sensitivity of $10^{-4} \mathrm{gm}$. Dye doped polymer films were fabricated by the free casting technique (FC). Polymer solution was prepared by dissolving the required amount of polymer $(7 \mathrm{gm})$ in $100 \mathrm{ml}$ of the used solvent.

The free casting (FC), involves casting a polymer solution in a flat bottomed glass cup (Petri dish) without imposing hydrodynamic stress on the liquid .

Solvent is allowed to evaporate under ambient conditions until the films harden Fig. (4).

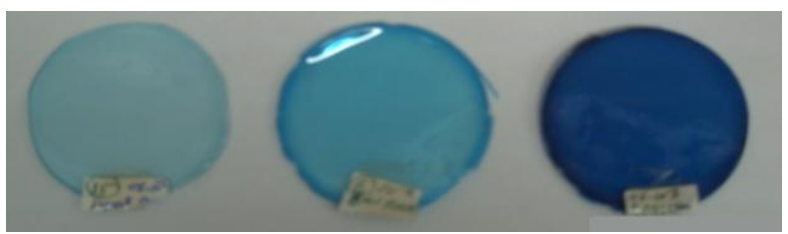

Fig.(4) The oxazine doped film in PMMA.

The thickness of the films produced by this method is dependent on concentration and the volume of the liquid in the dish. The liquid volume was (10) $\mathrm{ml}$, yielding film of different thicknesses.

The thickness of the films was measured with an electrical device (Mini-test 3000 microprocessor coating thickness) from electro, phyisk, Germany (ERICHSEN) Fig. (5).

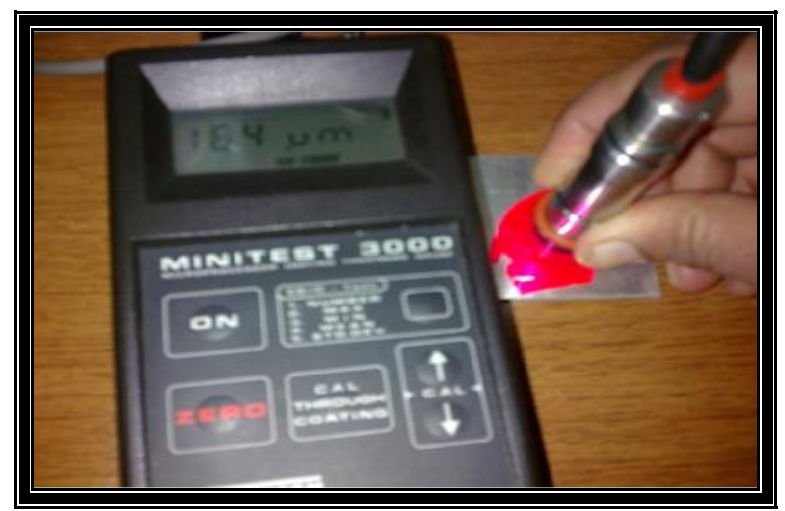

Fig. (5) The electrical device Minitest 3000 for measuring samples thickness.

The doping ratio was 1:2 dye to the polymer

\section{Results and Discussion}

Fig. (6), shows the absorption spectra of the dye doped polymer films in chloroform were carried out by using (UV/Vis SP - 3000, plus, 2003) Spectrophotometer Optima / Japan, which operates in wavelength range of $190-1100 \mathrm{~nm}$. The light source is TungstenHalogen and $D_{2}$ lamp. Its monochrometer is modified (turner type with 1200 lines $/ \mathrm{mm}$ holographic grating. Its detector is Silicon photodiode with automatically rotating Position cell holder [13].

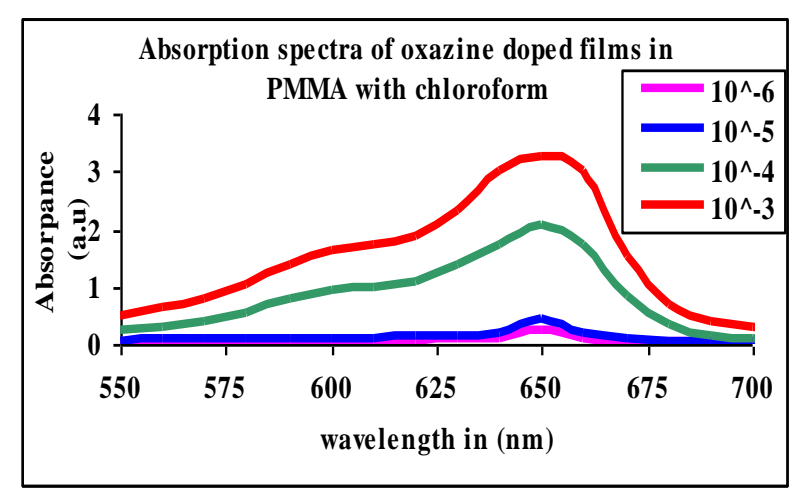

Fig. (6) Linear absorption spectra of the four different concentrations of the oxazine doped film.

Table (1) show nonlinear refractive index parameters for dye dopped polymer doped Films.

Table (1)

Nonlinear refractive index parameters for PMMA films doped with Ox. in Chloroform.

\begin{tabular}{|c||c||c||c||c||c||c|}
\hline $\begin{array}{c}\boldsymbol{C} \\
\mathbf{M} / \mathbf{L}\end{array}$ & $\begin{array}{c}\boldsymbol{L} \pm \boldsymbol{I} \\
\mathbf{c m}\end{array}$ & $\mathbf{T \%}$ & $\begin{array}{c}\boldsymbol{\alpha}_{\boldsymbol{o}} \\
/ \boldsymbol{c m}\end{array}$ & $\boldsymbol{L}_{\text {eff. }} \cdot \boldsymbol{c m}$ & $\boldsymbol{T}_{\boldsymbol{m a x}}$ & $\boldsymbol{T}_{\text {min }}$ \\
\hline \hline $10^{-6}$ & 0.03 & 0.83 & 6.14 & 0.027 & 1.143 & 0.43 \\
\hline \hline $10^{-5}$ & 0.014 & 0.71 & 23.37 & 0.012 & 1.125 & 0.025 \\
\hline \hline
\end{tabular}

\begin{tabular}{|c||c||c||c||c||}
\hline \hline $\boldsymbol{T}$ & $\Delta \boldsymbol{\phi}_{\boldsymbol{o}}$ & $\begin{array}{c}\boldsymbol{n}_{2} \\
\boldsymbol{c m}^{2} / \text { watt }\end{array}$ & $\boldsymbol{n}_{\boldsymbol{o}}$ & $\boldsymbol{X}^{3} \mathbf{c m}^{2} /$ watt \\
\hline \hline 0.714 & 1.76 & $2.65 \times 10^{-6}$ & 1.86 & $2.3 \times 10^{-09}$ \\
\hline \hline 1.1 & 2.71 & $9.04 \times 10^{-6}$ & 2.38 & $1.3 \times 10^{-08}$ \\
\hline
\end{tabular}

Fig. (7) shows the closed aperture Z-scan curve for these concentrations, while closed aperture for films of concentration $\left(10^{-4}\right.$ and $10^{-3}$ ) M/L were damaged (see Fig. (8)). 


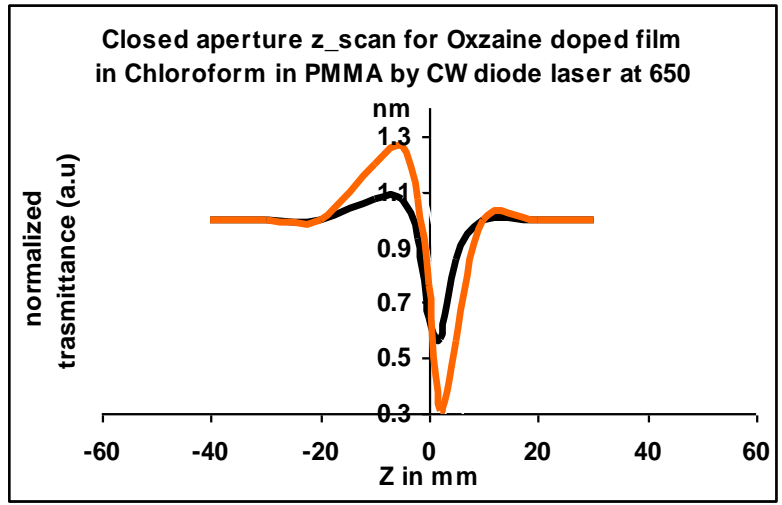

Fig.(7) Closed aperture z-scan curve for dye doped polymer film.

Fig. (7) indicates negative refractive index for films of concentrations $\left(10^{-6}\right.$ and $\left.10^{-5}\right) \mathrm{M} / \mathrm{L}$ Ox. doped with PMMA in Chloroform. Fig.(7) is in anology with the theoretical behavior in the dotted line in Fig.(2).

Measurements of the nonlinear refractive index $\mathrm{n}_{2}$, with concentrations $\left(10^{-6}\right.$ and $\left.10^{-5}\right)$ $\mathrm{M} / \mathrm{L}$ Ox doped in PMMA films were calculated using closed aperture Z-scan parameters shown in table 1,where: $\alpha_{0}, L$ eff , $\Delta \phi_{\mathrm{o}}, \Delta \mathrm{T}_{\mathrm{pv}}, \quad \mathrm{n}_{2}$, were calculated from equations: (13), (12), (9),(7) and (10) respectively, while $T_{p}$ and $T_{v}$ calculated from Fig.(7). The real part of the third order nonlinear susceptibility was calculated from this equation (5).

Linear refractive index $n_{0}$ was calculated from equation:

$\mathrm{n}_{\mathrm{o}}=1 / \mathrm{T}+\left[\left(1 / \mathrm{T}^{2}\right)-1\right]^{0.5}[14]$

Where $\mathrm{T}$ is the linear transmittance of the films.

Fig.(8) shows the damage which had happened in the samples of concentration $10^{-3}$ and $10^{-4} \mathrm{M} / \mathrm{L}$ enlarged by the electronic microscope in the center for crystal growth and thin films; Ministry of Science \& Technology, Baghdad, Iraq.

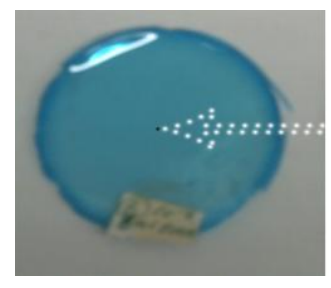

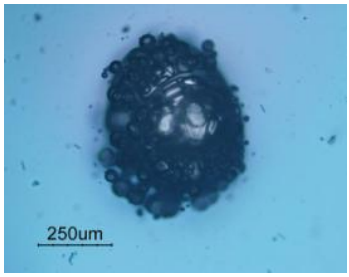

$10^{-4} \mathrm{M} / \mathrm{L}$
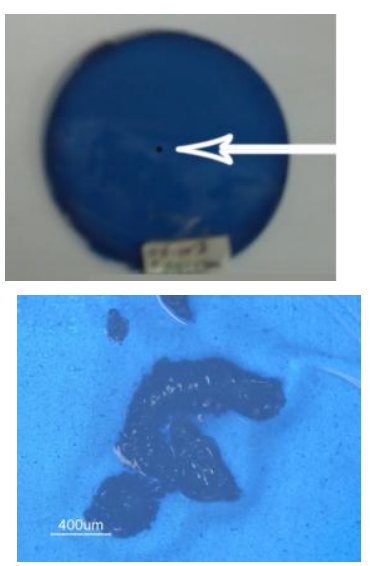

$10^{-3} \mathrm{M} / \mathrm{L}$
Fig. (8) The damaged doped films of concentrations $10^{-4}$ and $10^{-3} \mathrm{M} / \mathrm{L}$ as seen by the electrical microscope.

The results for the open aperture z-scan show that the four films exhibited saturation absorption as shown in Fig.(9).

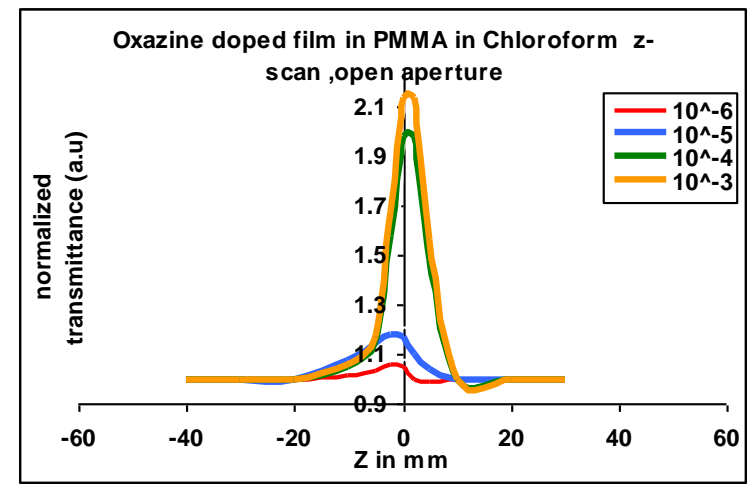

Fig.(9) Open aperture z-scan for oxazin doped films in PMMA by using cw diode laser at $650 \mathrm{~nm}$.

Doped films of concentration $10^{-4}$ and $10^{-3} \mathrm{M} / \mathrm{L}$ had damaged while doped films of concentration $10^{-5}$ and $10^{-6} \mathrm{M} / \mathrm{L}$ showed a negative nonlinearity and large nonlinear refractive index $\mathrm{n}_{2}$ of values $2.65 \times 10^{-6}$ and $9.04 \times 10^{-6} \mathrm{~cm}^{2} \mathrm{~W}^{1}$ respectively due to the self-defocusing process values. Also they showed large nonlinear susceptibility of values $2.3 \times 10^{-09}$ and $1.3 \times 10^{-08} \mathrm{~cm}^{2} /$ watt respectively. This result is in good agreement with the results of K Mutanchiang. [15].

The contribution of the observed third order nonlinearities is thermal in nature .The energy from the focused laser beam is transferred to sample through linear absorption and is manifested in terms of heating the medium leading to a temperature gradient and 
there by the refractive index changes across the sample which then acts as a lens (Kerr effect). The phase of propagating beam will be distorted due to the presence of this thermal lens [16]. Since the energy from the focused laser beam is transferred to sample through linear absorption. , films of concentration $10^{-4}$ and $10^{-3} \mathrm{M} / 1$ were damaged because the maximum absorbtion for these samples ocures at wavelengths around $650 \mathrm{~nm}$. This insure that the high concentration led to increasing film thickness and then increasing the phase shift and the nonlinear absorption.

With open aperture z-scan the investigated films showed that the nonlinear

absorption can be attributed to a saturation absorption process,

\section{Conclusions}

The nonlinear refractive index coefficient $n_{2}$, and the third order susceptibility, $\chi(3)$ for oxazine dye doped films was studied by Z-scan technique using a $650 \mathrm{~nm}$ diode laser. The Z-scan measurements indicated that the dyes exhibited negative nonlinear optical properties. The nonlinear absorption can be attributed to a saturation absorption process, while the nonlinear refraction leads to self_defocusing in this dye it is attributed to the thermal variation of refractive index in the medium.

The concentration dependent nonlinear refractive index was observed in this dye doped films. Films of high concentrations $10^{-4}$ and $10^{-3} \mathrm{M} / \mathrm{L}$ were damaged due to the correlation between the linear and nonlinear absorption where the maximum linear absorption wavelength of this dye is very close to the wavelength of the used laser, while $n_{2}$ for the films $10^{-5}$ and $10^{-6} \mathrm{M} / \mathrm{L}$ increased as the concentration of the dye was increase .This may be attributed to the fact that when the number of dye molecules increases, causing an increase in the films thickness which in turn increases the nonlinear phase shift causing an increase in the nonlinear refractive index.

The high values of nonlinear refractive index $\left(\mathrm{n}_{2}\right)$ for the $10^{-6}$ and $10^{-5} \mathrm{M} / \mathrm{L}$ compared with other optical materials indicating that the sample has a large nonlinear optical effect, which can be considered as a promising candidate for photonic device application. So the dye doped polymer films of oxazine with
PMMA have a high nonlinearity but for law concentrations.

\section{References}

[1] Achamma Kurian, Nibu A George, Binoy Paul, Paul, V. P. N. Nampoori And C. P. G. Vallabhan, "Fluorescence Efficiency and Photodegradation of Rhodamine 6G Doped PMMA Using a Dual Beam Thermal Lens", Technique Laser Chemistry Vol. 20(2-4), pp. 99-110, (2002).

[2] Sally A. Swanson, Greg M. Wallraff, Jian P. Chen, Weijie Zhang,Luisa D. Bozano, Kenneth R. Carter, Jesse R. Salem, Reymundo Villa, and J. Campbell Scott, "Stable and Efficient Fluorescent Red and Green Dyes for External and Internal Conversion of Blue OLED Emission" Chem. Mater, vol. 15,pp 2305-2312, 2003.

[3] R. Menzel, "Photonics", Springer, Berlin. 2001.

[4] M. Sheik-Bahae, A.A. Said, T.H. Wei, D.J. Hagan, and E.W. Van Stryland, "Sensitive Measurement of Optical Nonlinearities Using a Single Beam," IEEE Journal of Quantum Electronics, -26, pp760-769, 1989.

[5] Steven Richard Vigil, "Nonlinear-Optical Studies Of Organic Liquids And Polymer Optical Fibers", phd Thesis, Washington State University, Department of Physics, 2000.

[6] N.K. M. Naga Srinivas, Venugopal R., and D. Narayana R. saturable and reverse saturable absorption of rhodamine $\mathrm{B}$ in methanol and water, J. Opt. Soc. Am. B, Vol. 20, pp 2470-2479, 2003.

[7] Mansoor Sheik-Bahae, et. al., "Characterization Techniques and Tabulations for Organic Nonlinear Materials", Center for Research and Education in Optics and Lasers, University of Central Florida, pp 655-692, 1998.

[8] Kaladevi Sendhil,et al., "Low-threshold optical power limiting of $\mathrm{cw}$ laser illumination based on nonlinear refraction in zinc tetraphenyl porphyrin" , Optics \& Laser Technology, 38, pp 512-515,2006.

[9] Mansoor Sheik- aBahae, Michael P Hassaibeak,"Handbook of Optics, Vo.IV, Chapter 17,(2000).pp1-50. 
[10] M. Sheik-Bahae, et al., "Nonlinear refraction and optical limiting in thick media", Optical Engineering, Vol.30, pp 1228-1235, 1991.

[11] Michael R. Webb, "Interactions Between Oxazine Dyes And Sodium Dodecyl Sulfate Studied By Molecular Spectroscopy”, PhD Thesis, Union College, June, 2001.

[12] Uliich Brackmann," Lambdacxhrome Laser Dyes", Lambda Physik GmbH, 1986.

[13] Manual of SP_3000 Puls Uv/Vis Spectrophotometer Optima /Japan.

[14] Dawood Obied Altaify Master Thesis, "Nonlinear Optical Properties of CdS Thin Film Nanoparticles Using Z-Scan Techniqu, Submitted to the Institute of Laser, University of Baghdad, 2007.

[15] K.Milanchian,H.Tajalli , A. Ghandzadeh Gilaniand M.S, Zakerhamidi, 'Nonlinear optical properties of two oxazine dyes in aqueous solution and polyacrylamide hydrogel using single beam Z-scan", Volume 32, pp 12-17, November 2009.

[16] J. J. Park, PhD, "Photo-Induced Molecular Reorientation And Photothermal Heating As Mechanisms Of The IntensityDependent Refractive Index In Dye-Doped Polymers", Washington state university, Department of Physics and Astronomy, 2006.

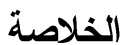

في هذا البحث العملي دراسة للصفات اللاخطية لأغثية الصبغة الليزرية الأوكسازين و المطعمة مع البوليمر بتر اكيز مختلفة بأستخدام المذيب الكلوروفورم (PMMA) و ذلك باستخدام طريقة ذات حساسية عالية تعرف بتقنية

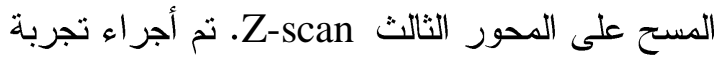
المسح على المحور الثالث باستخدام ليزر الدايود ذو لهو لهاه

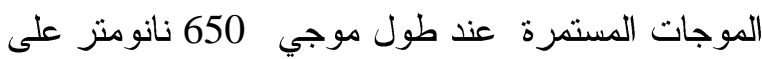

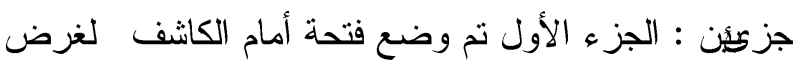
دراسة معامل الانكسار اللاخطي • في الجزء الثاني أزيلت

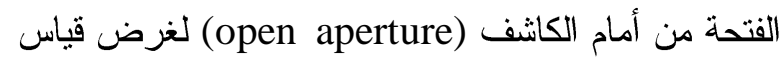
معامل الامتصاص اللاخطي. أظهرت التجارب في حالة وضع الفتحة أمام الكاثف إن أغشية الصبغة المطعمة تظهر التهر معامل انكسار لاخطي سالب (self-defocusing) للتز اكيز

$$
\begin{aligned}
& \text { الو اطئة , \& } \left.10^{-5} \mathrm{M} / \mathrm{L}\right) ، \text { بينما تلفت الأغشية ذات } \\
& \text { التز اكيز العاليةL/ M \& } 10^{-3} \text { 10. أظهرت التجارب ايضا }
\end{aligned}
$$

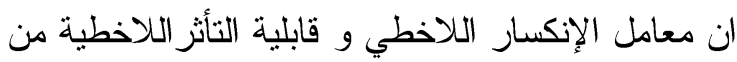

$$
\begin{aligned}
& \text { الدرجة الثالثة (third order susceptibility) تزمداد } \\
& \text { بزيادة التركيز وذلك لزيادة سمك الغشاء الذب يؤدي الى لى الى الته }
\end{aligned}
$$

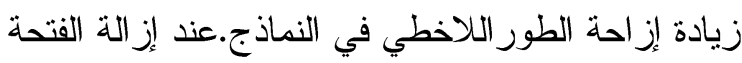

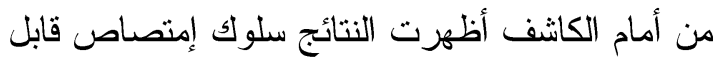

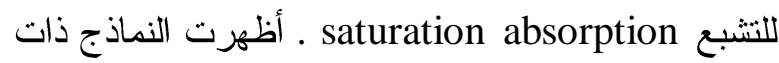

$$
\begin{aligned}
& \text { التر اكيز الواطئة فعالية لاخطية بصرية عالية مما يجعلها } \\
& \text { مؤهلة و اعدة في الأجهزة الضوئية. }
\end{aligned}
$$

